\title{
Research on the Communication Strategy of Sino-US Trade War from the Perspective of Framing Theory -Take People's Daily and The New York Times as Examples
}

\author{
Jiawei Wang \\ Haining Media Center, China
}

\begin{abstract}
The first-world economy, the United States, and the second economy, China (now first to some), by some metrics are at loggerheads for a long time. To some extent, the trigger is the Sino-US trade war provoked by former U.S. President Donald Trump in March 2018. Due to the profound differences in a political position, cultural concept, and communication habits, the two-state media of China and the U.S.: People's Daily and The New York Times, which play an important role in affecting international public opinion, show different orientations in choosing news materials, reporting strategies and media framework. To analyze these underlying causes, the author compares the selected editorials from the two-state media based on the framing theory in four dimensions - agency, identification, categorization, and generalization, to explore the different report frameworks, framework strategies, and the contributing factors. Therefore, the paper could provide some theoretical guidance and strategic suggestions for the international communication of China's media.
\end{abstract}

Keywords: the Sino-US trade war, People's Daily, The New York Times, framing theory, communication strategy

\section{Research Background}

On March 22, 2018, former U.S. President Donald Trump announced the imposition of tariffs on about $\$ 60$ billion of China's imports to reverse the trade deficit with China, unveiling the Sino-US trade war. Since then, China and the U.S. have successively introduced more stringent tariff policies, which deeply affected the relevant enterprises, from science and technology to agriculture, from chemicals industry to consumer goods and other fields.

After Mr. Trump's announcement, the Sino-US trade war has become the focus of media in both countries. Due to the profound differences in political position, cultural concept, and communication habits, media show different orientations in choosing news materials and media framework. To analyze these underlying causes, the author focuses on the two state media of China and the U.S.-People's Daily and The New York Times to explore their different report frameworks, framework strategies, and the contributing factors. Therefore, the author could provide theoretical guidance and strategic suggestions for the international communication of Chinese media. 
On August 23, 2018, the tariff categories valued at $\$ 16$ billion of both countries officially came into effect. During August 20 to 27, the U.S. held the first hearing on the $\$ 200$ billion tariff imposition of China's imports; simultaneously, the second-round tariff imposition categories valued at $\$ 200$ billion were in the critical time from formation to implementation. The reports of the two-state media were frequently concentrated on this issue.

Being influential newspapers in China and the U.S., the two-state media reports play important roles in affecting international public opinion. Based on indicators such as the issues involved and value orientation, three editorials ${ }^{1}$ from People's Daily and three ${ }^{2}$ from The New York Times are selected.

\section{Framing Theory}

Framing theory is a communication theory that initially emerged in the West in the late 1970s, first put forward by the anthropologist Bateson. In 1974, it was introduced into cultural sociology by Erving Goffman's work Frame Analysis. Then, it merged into journalism and communication research, which has become a vital point of view of qualitative research. Goffman believes that "framework" is important evidence for people to transform social reality into subjective reality. It is also the subjective interpretation and thinking structure of people or organizations (Xiao Wei, 30). Gammson further believes that the definition of the frame can be divided into two categories based on Goffman. One refers to the boundary, which means choice and represents the scope of material selection; the other is structure, used by people to explain the social phenomenons' structure, to report and comment on the activities of the external world (Tsang Kuo Jen, 20).

In many empirical studies, the comparative analysis of different news frameworks adopted by Entman R.M. is representative. He believes that there are two mechanisms of great significance to the construction and realization of news frameworks. One is the control of report scale, that is, to enlarge or weaken the importance or influence of an event through controlling the report quantity and order; the other is the presentation of specific information, which assists to construct different news reports from four factors: agency, identification, categorization, and generalization (Guo Qingguang, 211-212). This paper will study the selected editorials from the perspective of these four dimensions.

\section{Frame analysis of reports on Sino-US trade war}

\subsection{Frame analysis on reports from China's media}

\subsubsection{Agency}

Agency refers to the executor and responsible party of news events. After reading the three editorials, it is not hard to find that these reports attribute the perpetrators of the trade war to the

\footnotetext{
${ }^{1}$ U.S. experts and scholars criticize the U.S. government's trade policy: provoking a trade war is detrimental to the global common interests(2018-08-10); U.S. strays farther down the wrong path while U.S. enterprises against(2018-08-10); What is the trade war initiated by US essentially about(2018-08-13).
}

${ }^{2}$ How China Wins the Trade War(2018-08-08); Trump's Tariffs Are Paying Off for Century Aluminum(2018-08-22); When It Comes to a Trade War, China Takes the Long View(2018-08-08). 
U.S. side, such as the U.S. government, the U.S. international trade administrative department, and even Donald Trump.

The editorial U.S. experts and scholars criticize the U.S. government's trade policy: provoking a trade war is detrimental to the global common interests, believes that Chinese and American scholars, including Mary E. Lovely and David Dollar (Du Dawei), basically hold similar views: the U.S. trade war has caused many negative effects. The Chinese imports to the U.S. contain the added value of enterprises from other countries. U.S.' imposition is against the tides when economic globalization develops in depth and the interests of all countries increasingly intertwine, which is prone to lead to the fragmentation of the global trading system and is the "confidence killer" of all parties concerned. From this point of view, the U.S. is the agency, the initiator and the implementer of the trade war, and should also take the leading responsibility for the current negative situation.

The editorial U.S. strays farther down the wrong path while U.S. enterprises against pointed out that the hearing held by the office of the U.S. Trade Representative (USTR) is an approach to legitimize the trade war, but still cannot avoid opposite voices. The tariff measures largely harm the U.S. local small and medium-sized enterprises and significantly increase the production cost. USTR is the main decision-making department of the trade war. The U.S. is shooting itself in the foot as the trade war initiated by itself.

\subsubsection{Identity}

Entman points out that Identity refers to identifying the attributes of different related subjects in news events, that is, the positions and roles of all parties in news events, as well as the interactive relationship of them.

As the above two editorials mark, the U.S.- the trouble maker-provokes the trade war; however, the American enterprises, people, and the global trading system - the victims-take the consequence. This relationship defines the identities and situations of all parties in the trade war. The trade policy will affect global enterprises and consumers' interests in the global value chain, including American enterprises, and damage the global multilateral trading system and the process of global economic recovery. As far as the U.S. is concerned, the relevant content of Section 301 will increase the production cost of American enterprises in a "disproportionate" way, bring huge losses to enterprises as well as the Americans by reduced employment opportunities and rising commodity prices, which will directly affect their vital interests. Therefore, as an initiator, the US is the initiator of the war, and China, the American people, enterprises, and the global trading system are the victims of the consequences. The two sides interact in a clear role relationship.

The editorial What is the trade war initiated by the U.S. essentially about has a more profound positioning between China and the U.S. in the trade war. The U.S. tries to ensure its "absolute advantage" which can never be surpassed, and builds a "uni-polar world", while China is on the path of double win cooperation; in the context of economic globalization, Sino-US economic and trade cooperation makes China and the U.S. deeply integrate, but from the view of the U.S., it is still the law of the jungle. What the U.S. has done shows the unjust logic of power, which leads to the wrong judgment of the White House on the world order and China's role in the 21 st century. As long as China affects the global hegemony of the U.S., the U.S. will stifle and suppress China at all costs. Therefore, the roles and relations can be expressed as: the U.S. 
is the strong one who strives to maintain its hegemonic position, and China is the weak one who is mistaken for hegemonic intention.

\subsubsection{Categorization}

Categorization refers to the process of classifying news events into different categories and attaching labels. From the perspective of China's state media, the U.S. policy of provoking a trade war is a "lose-lose" behavior of "break the rule-based order".

The editorial U.S. experts and scholars criticize the U.S. government's trade policy: provoking a trade war is detrimental to the global common interests, judges the U.S. behavior through qualitative keywords. Such negative expressions as "provoke", "destructive decline", "disruptive impact," and "wanton shock of the current multilateral trading system" portray the U.S. as a "killer" who destroys the global trading system and geostrategic order.

China's state media, People's Daily, defines the nature and inevitable consequences of the incident as "lose-lose". At the beginning of the editorial U.S. strays farther down the wrong path while U.S. enterprises against, it is mentioned that "no one in the world, except the White House, may believe that there will be a winner in the trade war". The 82 speeches of enterprise representatives at the hearing also showed that the imposition of tariffs on Chinese imports would inevitably impact the economic development of the U.S. The editorial U.S. experts and scholars criticize the U.S. government's trade policy: provoking a trade war is detrimental to the global common interests, holds that most of the global economic growth is driven by the U.S. and China. If they fall into a trade war, both countries will lose, and so will the world economy.

\subsubsection{Generalization}

Generalization refers to explaining the origin and essence of news events, which is often expressed as an explanation of the historical background and realistic reasons of news texts. China's state media analyzes the essence, background and causes of the Sino-US trade war beyond the economic level to the political system and national interests' level, which shows that the deep motivation for the U.S. to provoke the trade war is due to the domestic political needs and the purpose of suppressing China's development.

The editorial What is the trade war initiated by U.S. essentially about points out that out of the political consideration of stifling China, the White House regarded China as a "strategic competitor" and said that China is a "revisionist country" that challenges the status and influence of the U.S. and intends to erode the security and prosperity of the U.S. U.S. must contain the transcendence of its opponents at all levels. Therefore, the Sino-US trade war is not only to narrow the trade deficit but also to take measures to curb China's development in a broader and deeper scope.

\subsection{Frame analysis on reports from the U.S.' media}

\subsubsection{Agency}

According to the three selected editorials, American media believe that China and the U.S. should jointly undertake the main body of trade war As the time sequence of the news events, the US is the instigator and undertaker of most consequences of the whole incident. At the 
same time, China is not only responding passively; it has also conducted active responses and precise strikes.

In the editorial How China Wins the Trade War, Mr. Trump exhorts his supporters that tariffs "mean jobs and great wealth." In the editorial, Trump' s Tariffs Are Paying Off for Century Aluminum also points out that the Trump administration has taken a series of actions to raise tariffs in order to curb China's aluminum overcapacity and stop imports of cheap metal from China.

Unlike the Chinese reports, the U.S. media believe that China is not just passively bearing the consequences but actively or even strategically responding. First of all, the intention and motivation of the Chinese government to take the reciprocal "counterattack" have achieved good effect. The editorial When It Comes to a Trade War, China Takes the Long View points out that "China targets Trump's interest groups with surgical precision". By aiming soybeans and pork, Beijing struck at Trump country in the Midwest while going after a smaller export like Kentucky bourbon hit the district of the Senate majority leader, Mitch McConnell. Secondly, instead of closing down the Chinese market as the U.S. envisioned, the Chinese leadership has deepened its commitment to the international supply chain and expanded foreign investment, including the approval of Tesla and the German chemical giant BASFfull ownership without the need for a local joint-venture partner. These measures have successfully reshaped the national image of "openness" and "fairness", and have received a positive response in international public opinion. Therefore, China is not entirely passive in bearing the consequences of the trade war.

From the above analysis, both the U.S. and China should be responsible for the trade war.

\subsubsection{Identity}

From the perspective of Identity, two different interpretation paths can be concluded. The first is that the U.S. government is the promisor and practitioner, and the U.S. local enterprises are the beneficiaries. The U.S. government, represented by Mr. Trump, made promises before and during the trade war, which benefited relevant industries and enterprises in the U.S.

The editorial Trump's Tariffs Are Paying Off for Century Aluminum believes that Century has faced years of layoffs. Its smelter here has several times been on the brink of shutting down. It was not until Mr. Trump decided to impose tariffs of 10 percent on aluminum and 25 percent on steel that the company received the lifeline it was looking for.

The second interpretation holds that as an objective situation, the trade war's complex influence and multiple results are shared and digested by all stakeholders of China and the U.S.

First of all, the American people, families, enterprises, and industries primarily affect subjects. The editorial How China Wins the Trade War points out the tariffs imposed by the Trump administration affect many American companies that own factories in China. These companies will pass the rising manufacturing costs along to American consumers in the form of higher prices. For example, a 20-percent tariff on washing machines is followed by a 16.4-percent spike in consumer prices. Many Americans paid for the trade war.

Secondly, the political interest groups represented by Mr. Trump are also the leading undertakers of the consequences of the trade war. The U.S. government did not achieve the 
expectation but was precisely countered by China. Most of the products imported from China by the U.S. are included in the value created by other regions (including the U.S.), so the tariff will also have a negative impact on the economic interests of the U.S. From the perspective of political interests, the editorial When It Comes to a Trade War, China Takes the Long View points out that by aiming soybeans and pork, Beijing struck at Trump country in the Midwest, while going after a smaller export like Kentucky bourbon hit the district of the Senate majority leader, Mitch McConnell.

Thirdly, China's national image and its position in international public opinion are potential beneficiaries. the U.S. wants to portray China as a closed market, but it allows the Chinese government to improve its national image. In the first round of retaliatory tariffs, China avoided cracking down on imports from foreign factories; Beijing allowed foreign investors access to banking, agriculture, automobile and heavy industry more easily, such as Tesla and the German chemical giant BASF, giving those companies full ownership without the need for a local joint-venture partner. The U.S. media believe that as the trade war escalates, China seeks to "shift the blame" and portray itself as a champion of "openness, freedom and fairness".

\subsubsection{Categorization}

There are many explicit generalizations and implicit hints about the nature of the Sino-US trade war in the editorials. Overall, the U.S. media's characterization of the trade war is: some are promising, but the essence is negative.

Firstly, some are promising. In the editorial How China Wins the Trade War, the reporter uses "jobs and great wealth" to show that trade war can promote employment and accumulate wealth; through "hurt China" and "do a bit of damage", the decline of American demand for importing Chinese products has hit China's interests; The editorial Trump's Tariffs Are Paying Off for Century Aluminum uses the words such as "victory", "revival", "dividend", "rehire" and "new signs of hope" to describe the revival opportunities and development space of Century aluminum in the trade war.

Secondly, the essence is negative. The editorial How China Wins the Trade War describes China's response to the trade war and its impact on China with the words like "win" and "weather difficulties", "skillfully" and "backfire", indicating that Trump's tariff has not achieved the expected effect. China's more ingenious policy may become the winner. The editorial Trump's Tariffs Are Paying Off for Century Aluminum uses the term "uncertain" to describe the prospect of the American aluminum industry. "A drag on profits" is the actual consequence of tariff policy, and the U.S. government is still "under pressure". The editorial When It Comes to a Trade War, China Takes the Long View describes a prosperous and reviving Shanghai, which refers to today's China and potentially exaggerates the relatively unfavorable situation of the U.S.

\subsubsection{Generalization}

In the three selected editorials, the essence, the retrospect and prospect of the trade war have been discussed many times. On the surface, the trade war is an economic phenomenon whose roots go far beyond the economics field and involve politics, history, culture, and other aspects.

Beyond the economic interests, the trade war has also been reflected in history and culture, behind the international competition between the two economies, originating from the Opium 
War, the largest trade war in Chinese history. The editorial When It Comes to a Trade War, China Takes the Long View points out that the trade war in the 21st century is like "history repeating itself," and the competition has continued with the reform and development of China till it broke out completely today. On the surface, the trade war is a contradiction between tariff and interest. Still, it is influenced by the nationalist ideas of late developing countries like China, affecting the decision-making and practice of trade war. The unequal treaties have fueled China's sense of historical grievance and patriotic ambitions ever since.

It should be noticed that the cause of the trade war is also the ideological differences between China and the U.S. The U.S., a powerful capitalist country, takes pluralistic liberalism as its basic value criterion, and takes "liberalization" and "pluralism" as its golden rule in the practice of public policy; China, a socialist country with strong government, whose public policy is mainly about maintaining macro-control and properly coordinating with market economy.

Besides, the logic of trade war is also affected by national politics and international competition and even leads to the structural change of global power distribution in the future. The editorial How China Wins the Trade War points out that by skillfully gaming with the U.S., China will improve its standing in the world to make and build the future. The editorial When It Comes to a Trade War, China Takes the Long View adopts the development of Shanghai's Former French Concession to imply the rejuvenation of China and indicates that China may have the strength to fight against the West now from the perspective of the protagonist Ye Fangsu.

\section{Conclusion}

The state media of China and the U.S. have different characterization, plot structure, and ending set. Overall, Chinese media portray the U.S. as the destroyer of trade rules and peaceful development value norms. At the same time, China is a champion of regulations and standards, which will significantly negatively impact the international economy and politics. Comparatively speaking, the reporting framework of American media is more complex: both China and the U.S. are responsible for the trade war. China is not entirely "innocent". The multiple effects of the trade war affect all relevant stakeholders of China and the U.S., and its consequences may bring about a new round of changes in the international situation and the global power structure. Based on this, there are many advantages and experiences that Chinese media can learn.

Firstly, objectivity is one of the core concepts of journalistic professionalism, and factual reporting is the core and cornerstone of journalistic activities (Guo Zhenzhi, 72). American media quoted a large number of empirical data, including statistical data, real cases, and civilian comments, to support news reports' position and value. In contrast, there are still some deficiencies in China's fact reports. The conclusions and judgments of the editorials often go beyond the scope of fact. For Western readers, fact reporting is more likely to be recognized and trusted. Therefore, to attract more international audiences, China's media can adopt the implicit strategy instead of explicit, which means reporting facts and leaving the space of judgment for readers.

Secondly, journalistic professionalism holds that news should genuinely, ultimately, and comprehensively reflect the social truth. News reports should adopt diverse sources, follow the 
principle of balance and diversity, and present objective phenomena thoroughly and evenly (Kovach B. and Rosenstiel T., 190). The U.S. report comprehensively covers the pros and cons of domestic and overseas, official and non-governmental sources, which have firm persuasion. Although China has made significant progress in diversified reporting, the official news sources are still more than folk, positive reports more than negative, domestic more than foreign. Thus, China should endeavor to take a humble attitude, maintain the interactive balance between eastern and western, domestic and international, official and folk sources, organize interpretation texts from multiple perspectives, and construct a more diverse and objective space for cognitive image (Feng Ruogu, 201).

Finally, China's media should fully grasp the social and cultural context of the audience through cultural proximity, explore the content close to the audience's understanding from the theme and value level, and reduce the distance between China's position and overseas audience (Zhang Kun, 397). Based on fully understanding the cultural characteristics of the audience in other countries, Chinese reports could select and produce communication contents that meet the needs, tendencies, and expectations of them, enhance the attraction of cross-cultural communication, and then promote the ability and expand the effect of international communication.

\section{Acknowledgment}

After almost two years' study and writing, the paper was finally accomplished. Thus here, I would like to express my sincere gratitude towards the people who helped me.

First and foremost, I would first like to thank my paper advisor Ruogu Feng, lecturer of Sociology Department at Beijing University of Technology, who influenced me with his insightful ideas, guided me with practical academic advice, and enlightened me when I was confused during the writing procedure.

I would also like to thank my friend Jinxy who was involved in the survey of this research project. Without her passionate participation and input, our work could not be successfully conducted.

Finally, I must express my very profound gratitude to my parents for providing me with unfailing support and continuous encouragement during the process of researching and writing. This paper would not be accomplished without them.

\section{References}

Robert M. Entman, (1991), U.S. Coverage of International News: Contrasts in Narratives of the Kal and I ran Air Incidents, Journal of Communication, 1991, vol. 41, pp. 6-27.

Miskimmon, A., O'Loughlin, B., \& Roselle, L., (2013). Strategic narratives: Communication power and the new world order. Routledge, New York.

Kovach B. and Rosenstiel T., (2001). The Elements of Journalism: What Newspeople Should Know and the Public Should Expect. Crown Publishers, New York. 


\section{iorhs}

\section{4th International Conference On Research In}

HUMANITIES \& SOCIAL SCIENCES

University Press, Wuhan, pp. 397.

Tsang Kuo Jen, (1998). News Report and Reality Construction: A Theoretical Perspective of News Framework. School of Communication of National Chengchi University, Taipei, pp. 20.

Xiao Wei, (2010). On Erving Goffman's Frame Analysis, International Press, vol. 12, pp. 30-36.

Guo Qingguang, (2011). Journalism and Communication. Renmin University of China Press, Beijing, pp. 211-212.

Guo Zhenzhi, (2000). Supervision by Public Opinion, Objectivity and Journalistic

Professionalism, T.V. Research, vol. 3, pp. 70-72. 